Original Article

\title{
DEVELOPMENT AND EVALUATION OF NOVEL ESTIMATION TECHNIQUES FOR IN VITRO DISSOLUTION STUDY AND VALIDATION PROTOCOL FOR ESCITALOPRAM AS ANTIDEPRESSANT DRUG AND THEIR FORMULATION
}

\author{
SHRIRAM H. BAIRAGI ${ }^{*}$, R. S. GHOSH ${ }^{2}$ \\ ${ }^{1 *}$ Research Scholar, Carrier Point University, Kota, Rajasthan. ${ }^{2}$ Department of Pharmacy, Carrier Point University, Kota, Rajasthan \\ Email: shrirambairagi@gmail.com \\ Received: 19 Apr 2020, Revised and Accepted: 24 Jun 2020
}

\section{ABSTRACT}

Objective: To develop and validate the RP-HPLC method and in vitro dissolution study for escitalopram as antidepressant drug and their formulation.

Methods: The chromatographic separation was done by using a C-18, $150 \mathrm{~mm}$ column and a mobile phase consisting of phosphate buffer (40\%) and acetonitrile HPLC grade (60\%). Detection was carried out at $211 \mathrm{~nm}$ with a flow rate of $1 \mathrm{ml} / \mathrm{min}$ with an injection of $20 \mu \mathrm{ll}$. The method was validated with different parameters such as linearity, precision, accuracy, robustness, and limit of detection (LOD), the limit of quantification (LOQ) according to ICH guidelines.

Results: The linear calibration curve was obtained in the concentration range of $0-50 \mu \mathrm{g} / \mathrm{ml}$ and gave an average correlation factor 0.992 . The retention time was observed at $2.96 \mathrm{~min}$. The Minimum concentration level at which the analyte can be reliably detected (LOD) and quantified (LOQ) were found to be 0.03 and $0.09 \mu \mathrm{g} / \mathrm{ml}$, respectively. The relative standard deviation of intra and the inter-day assay was found to be less than 2. The dissolution studies show moderate dissolution (23.4\%) after $45 \mathrm{~min}$, but it reaches a plateau after approximately 25 min.

Conclusion: This method was found to be simple, rapid and economic with less run time. The validated parameters manifest the method is reliable linear, accurate and precise as well as robust with minor variations in chromatographic parameters. Therefore, the developed method can be applied for both routine analysis and quality control assay and it could be a very powerful tool to investigate the stability of escitalopram.

Keywords: Escitalopram, RP-HPLC, Dissolution studies, Anti-depressant activity

(C) 2020 The Authors. Published by Innovare Academic Sciences Pvt Ltd. This is an open access article under the CC BY license (http://creativecommons.org/licenses/by/4.0/) DOI: http://dx.doi.org/10.22159/ijpps.2020v12i8.37964. Journal homepage: https://innovareacademics.in/journals/index.php/ijpps.

\section{INTRODUCTION}

Escitalopram is chemically (1S)-1-[3-(dimethylamino)propyl]-1-(4fluorophenyl)-1,3-dihydro-2-benzofuran-5-carbonitrile. The typical chemical structure is shown in fig. 1 . The drug having the molecular formula: $\mathrm{C}_{20} \mathrm{H}_{21} \mathrm{FN}_{2} \mathrm{O} \bullet \mathrm{C}_{2} \mathrm{H}_{2} \mathrm{O}_{4}$. Escitalopram is a selective serotonin reuptake inhibitor (SSRI). The S-enantiomer of racemic citalopram [1]. In the treatment of depression and anxiety, it is used to restore serotonergic functions. Escitalopram is approximately 150 times more potent than citalopram's R-enantiomer. Amongst SSRIs, escitalopram exerts the highest degree of selectivity for the serotonin transporter (SERT) relative to others [2]. Escitalopram also differentiates itself from other SSRIs via allosteric action on its target; this may be the mechanism responsible for its observed superior efficacy and faster onset compared to other SSRIs.

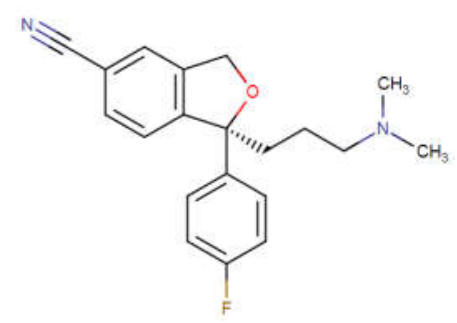

Fig. 1: Structure of escitalopram

Literature survey reveals spectrophotometric, RP-HPLC [3-13], and HPTLC [14] methods for these compounds either individually or in combination with other dosage forms. The literature review does not show any stability indicating RP-HPLC method for quantification of escitalopram. Hence, it was felt that there was a need for a new analytical method by RP-HPLC. The present research work was aimed to develop a single, simple, fast, rapid suitable stabilityindicating RP-HPLC method for the determination of escitalopram. The developed method was validated concerning specificity, the limit of detection (LOD), the limit of quantitation (LOQ), linearity, precision, accuracy and robustness. The method is in the accordance with ICH guidelines [15-17].

\section{MATERIALS AND METHODS}

\section{Chemicals and reagents}

Samples of escitalopram pure drugs were received from, Cipla Limited (Mumbai, India). HPLC-grade acetonitrile was purchased from Merck (Mumbai, India). Ortho-phosphoric acid was purchased from Qualigens Fine Chemicals (Mumbai, India). HPLC grade water was prepared by using a Millipore Milli-Q plus purification system.

HPLC instrumentation and conditions

The HPLC system employed was Hitachi L2130 with D elite 2000 Software with isocratic with UV-visible detector (L-2400).

Standard and sample preparation for UV-spectrophotometer analysis

The standard and sample stock solutions were prepared separately by dissolving standard and sample in a solvent in the mobile phase diluting with the same solvent. After the optimization of all conditions for UV analysis, it scanned in the UV spectrum in the range of 200 to $400 \mathrm{~nm}$. This has been performed to know the maxima of escitalopram so that the same wavenumber can be utilized in HPLC UV detector for estimating the escitalopram. While scanning the escitalopram solution, we observed the maxima at 211 $\mathrm{nm}$. The UV spectrum has been recorded on ELICO SL-159 make UVVisible spectrophotometer model UV-2450. 


\section{Standard Solution preparation}

$25 \mathrm{mg}$ of escitalopram standard was transferred into $25 \mathrm{ml}$ volumetric flask, dissolved and makeup to volume with mobile phase. Further dilution was done by transferring $1 \mathrm{ml}$ of the above solution into a $10 \mathrm{ml}$ volumetric flask and makeup to volume with mobile phase.

\section{Sample solution preparation}

20 tablets of the marketed drug were weighed and the average weight was calculated. The sample equivalent to $25 \mathrm{mg}$ of escitalopram was accurately weighed and transferred into a $25 \mathrm{ml}$ volumetric flask. About $20 \mathrm{ml}$ of diluent was added and sonicated to dissolve drug completely and the volume was made up to the mark with diluent, which gave the stock solution of $1000 \mathrm{ppm}$. The solution was mixed well and filtered through a $0.45 \mu \mathrm{m}$ filter. $1 \mathrm{ml}$ of the above stock solution was pipetted into a $10 \mathrm{ml}$ volumetric flask and diluted up to the mark with diluent to prepare $100 \mathrm{ppm}$ solution. Further $1 \mathrm{ml}$ of prepared $100 \mathrm{ppm}$ solution was pipetted into a $10 \mathrm{ml}$ volumetric flask and diluted up to the mark with diluent, which gave 10 ppm escitalopram working standard solution. It was mixed well and filtered through a $0.45 \mu \mathrm{m}$ filter.

\section{Preparation of phosphate buffer}

About $6.8 \mathrm{gm}$ of potassium dihydrogen orthophosphate was weighed and transferred into a $1000 \mathrm{ml}$ beaker, dissolved and diluted to $1000 \mathrm{ml}$ with HPLC water. The $\mathrm{pH}$ was adjusted to 3.0 with orthophosphoric acid.

\section{Preparation of the mobile phase}

$400 \mathrm{ml}(40 \%)$ of the above buffer and $600 \mathrm{ml}$ of acetonitrile HPLC $(60 \%)$ were mixed well and degassed in an ultrasonic water bath for $15 \mathrm{~min}$. The solution was filtered through a $0.45 \mu \mathrm{m}$ filter under vacuum filtration [18].

Diluent preparation: Mobile phase as diluent

\section{RESULTS}

\section{Initialization of the instrument}

The HPLC instrument was switched on. The column was washed with HPLC water for $45 \mathrm{~min}$. The column was then saturated with the mobile phase for $45 \mathrm{~min}$. The mobile phase was run to find the peaks. After $20 \mathrm{~min}$ the standard drug solution was injected in HPLC.

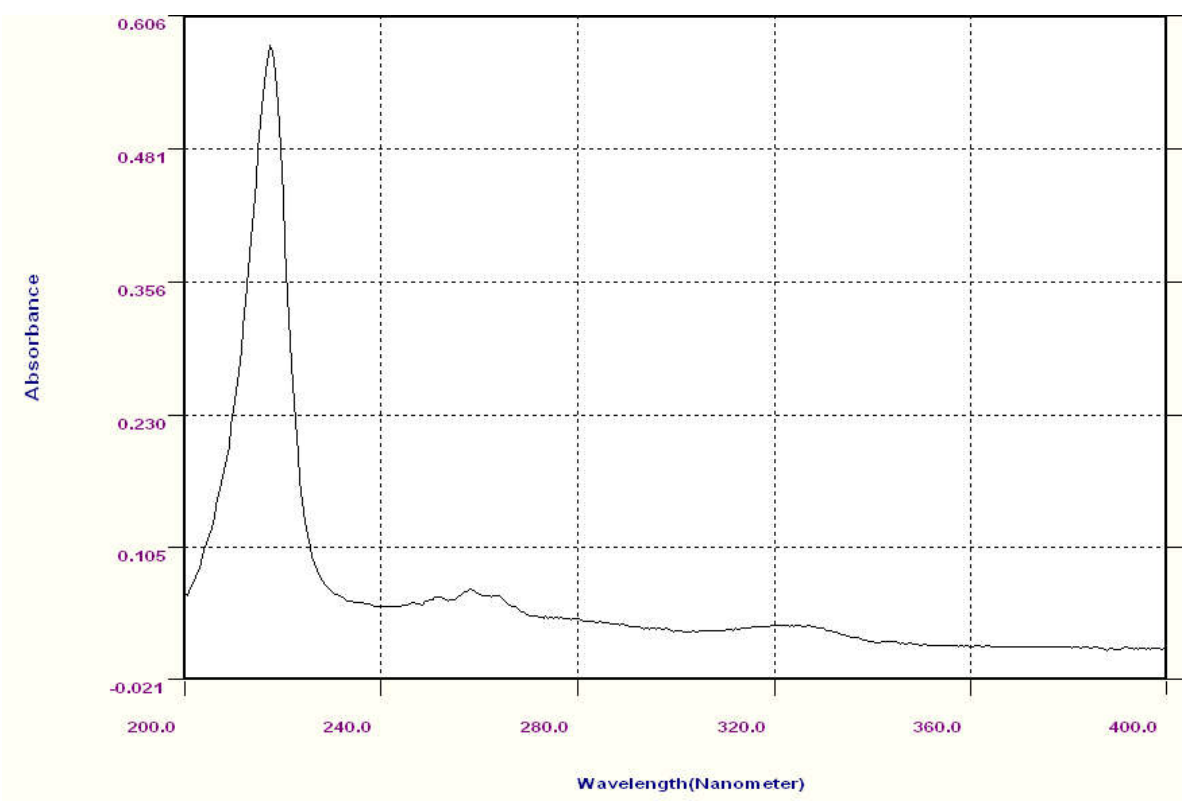

Fig. 2: Chromatogram escitalopram

Table 1: Optimized chromatographic conditions

\begin{tabular}{ll}
\hline Column: & C18 Develosil ODS HG-5 RP $150 \mathrm{~mm} \times 4.6 \mathrm{~mm} 5 \mu \mathrm{m}$ particle size \\
Mobile Phase: & Buffer: Acetonitrile $(60 ; 40)(\mathrm{pH} 2.9)$ \\
Flow Rate: & $1.0 \mathrm{ml} / \mathrm{min}$ \\
Wavelength: & $211 \mathrm{~nm}$ \\
Injection volume: & $20 \mu \mathrm{l}$ \\
Run time: & $10 \mathrm{~min}$ \\
Column temperature: & Ambient \\
\hline
\end{tabular}

Table 2: Different trials for chromatographic conditions

\begin{tabular}{|c|c|c|c|c|c|}
\hline Column used & Mobile phase & Flow rate & Wavelength & Observation & Result \\
\hline Waters $\mathrm{C} 18,5 \mu \mathrm{m}, 25 \mathrm{cmx} 4.6 \mathrm{~mm}$ i.d. & Methanol: Water $=80: 20$ & $0.5 \mathrm{ml} / \mathrm{min}$ & $211 \mathrm{~nm}$ & Low response & Method rejected \\
\hline Waters $\mathrm{C} 18,5 \mu \mathrm{m}, 25 \mathrm{~cm} \times 4.6 \mathrm{~mm}$ i.d. & ACN only & $0.5 \mathrm{ml} / \mathrm{min}$ & $211 \mathrm{~nm}$ & Very low response & Method rejected \\
\hline Waters $\mathrm{C} 18,5 \mu \mathrm{m}, 25 \mathrm{~cm} \times 4.6 \mathrm{~mm}$ i.d. & $\mathrm{ACN}:$ water $=50: 50$ & $1.0 \mathrm{ml} / \mathrm{min}$ & $211 \mathrm{~nm}$ & Tailing peak & Method rejected \\
\hline Waters $\mathrm{C} 18,5 \mu \mathrm{m}, 25 \mathrm{~cm} \times 4.6 \mathrm{~mm}$ i.d. & ACN: acetate buffer $=50: 50$ & $1.0 \mathrm{ml} / \mathrm{min}$ & $211 \mathrm{~nm}$ & Broad Peak & Method rejected \\
\hline Waters $\mathrm{C} 18,5 \mu \mathrm{m}, 25 \mathrm{~cm} \times 4.6 \mathrm{~mm}$ i.d. & $\begin{array}{l}\text { ACN: phosphate buffer }= \\
60: 40(\mathrm{pH} 2.9)\end{array}$ & $1.0 \mathrm{ml} / \mathrm{min}$ & $211 \mathrm{~nm}$ & Good response & Method accepted \\
\hline
\end{tabular}




\section{Method validation}

\section{Accuracy and recovery study}

To determine the accuracy of the proposed method, recovery studies were carried out by adding different amounts (80\%, 100\%, and $120 \%)$ of pure drug of escitalopram were taken and added to the pre-analyzed formulation of concentration $10 \mu \mathrm{g} / \mathrm{ml}$. From that percentage, recovery values were calculated. The results were shown in table 3.

\section{Precision}

As per USP, it is the degree of agreement among individual test results obtained upon repeated application of analytical methods to multiple samplings of a homogenous sample or measure of the extent to which the data values are close to each other for many measurements (under similar conditions).

\section{Preparation of working standard of $10 \mathrm{ppm}$ of escitalopram}

$25 \mathrm{mg}$ of escitalopram working standard was accurately weighed and transferred into a $25 \mathrm{ml}$ volumetric flask, and about $20 \mathrm{ml}$ of diluent was added to it and sonicated to dissolve drug completely and volume was made up to the mark with the same solvent which gave a Stock solution of $1000 \mathrm{ppm} .1 \mathrm{ml}$ of the above stock solution was pipetted into a $10 \mathrm{ml}$ volumetric flask and was diluted up to the mark with diluents to prepare 100 ppm solution. Further $1 \mathrm{ml}$ of prepared $100 \mathrm{ppm}$ solution was pipetted into a $10 \mathrm{ml}$ volumetric flask and was diluted up to the mark with diluents, which gave $10 \mathrm{ppm}$ escitalopram working standard solution. The solution was mixed well and filtered through a $0.45 \mu \mathrm{m}$ filter.

\section{Procedure}

The standard solution was injected for five times and measured the area for all five injections in HPLC. The \%RSD for the area of five replicate injections was found to be within the specified limits.

\section{Acceptance criteria}

The $\%$ RSD for the area of five standard injections results should not be more than $2 \%$.

Table 3: Accuracy study of escitalopram

\begin{tabular}{|c|c|c|c|c|}
\hline \multirow[t]{2}{*}{ Sample ID } & \multicolumn{2}{|c|}{ Concentration $(\mu \mathrm{g} / \mathrm{ml})$} & \multirow{2}{*}{$\begin{array}{l}\% \text { recovery of } \\
\text { pure drug }\end{array}$} & \multirow[t]{2}{*}{ Statistical analysis } \\
\hline & Pure drug & Formulation & & \\
\hline $\mathrm{S}_{1}: 80 \%$ & 8 & 10 & 99.13 & Mean ${ }^{*}=98.94667 \%$ \\
\hline $\mathrm{S}_{2}: 80 \%$ & 8 & 10 & 98.79 & $\mathrm{SD}=0.171561$ \\
\hline $\mathrm{S}_{3}: 80 \%$ & 8 & 10 & 98.92 & $\%$ R. SD $=0.1733$ \\
\hline $\mathrm{S}_{4:} 100 \%$ & 10 & 10 & 99.72 & Mean $*=99.76 \%$ \\
\hline $\mathrm{S}_{5}: 100 \%$ & 10 & 10 & 99.81 & $\mathrm{SD}=0.045826$ \\
\hline$S_{6}: 100 \%$ & 10 & 10 & 99.75 & $\%$ R. SD $=0.0459$ \\
\hline $\mathrm{S}_{7:} 120 \%$ & 12 & 10 & 99.36 & Mean* $=99.37667 \%$ \\
\hline$S_{8}: 120 \%$ & 12 & 10 & 99.28 & $\mathrm{SD}=0.105987$ \\
\hline$S_{9}: 120 \%$ & 12 & 10 & 99.49 & $\%$ R. SD $=0.1066$ \\
\hline
\end{tabular}

*mean assay values of 3 replicates $(n=3)$.

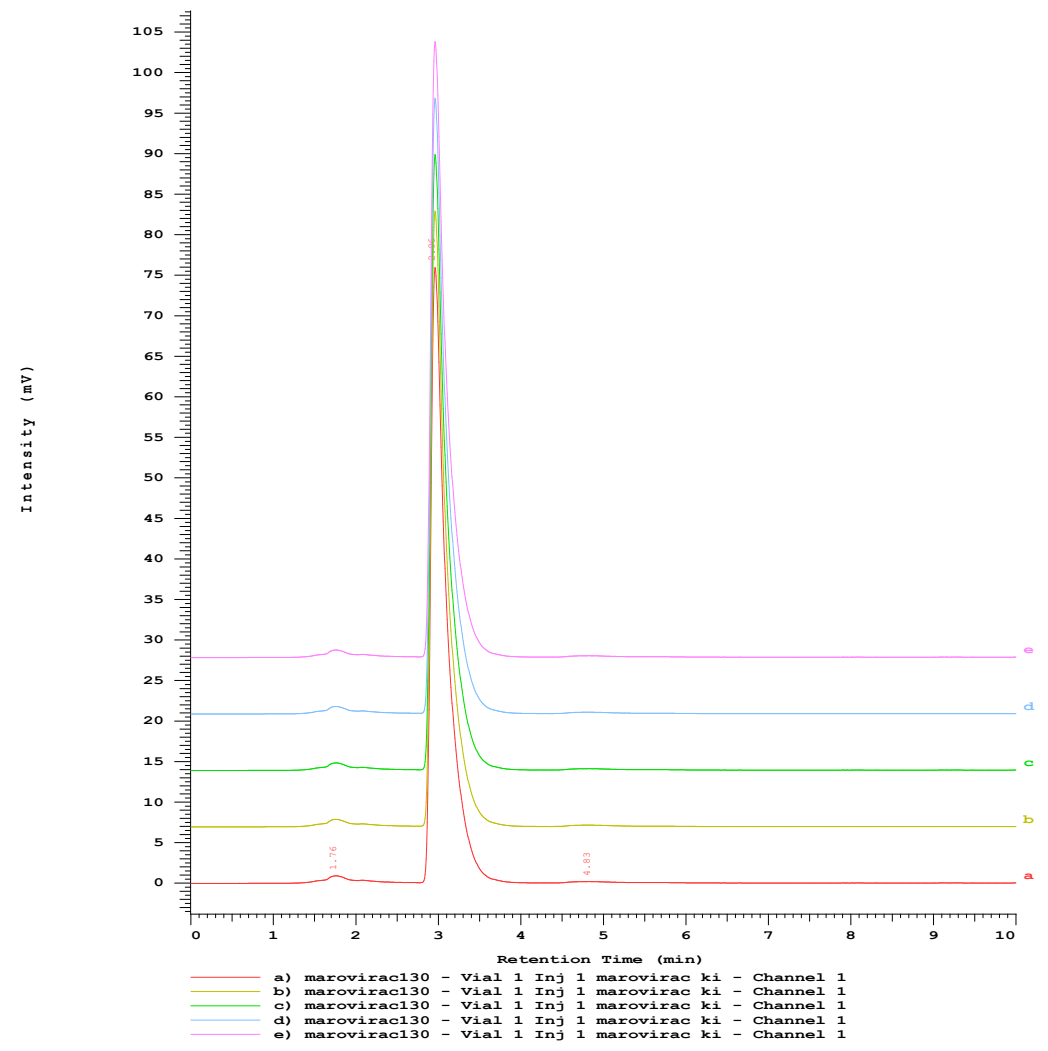

Fig. 3: Repeatability for escitalopram 
Table 4: Precision results

\begin{tabular}{lll}
\hline HPLC injection replicates of escitalopram & Retention time & Area \\
\hline Replicate-1 & 2.96 & 1025457 \\
Replicate-2 & 2.94 & 1003224 \\
Replicate-3 & 2.97 & 995798 \\
Replicate-4 & 2.96 & 992259 \\
Replicate-5 & 2.97 & 998740 \\
Average & 2.958 & 1003096 \\
Standard Deviation* & 0.013038 & 13131.13 \\
\% RSD & 0.440784 & 1.309061 \\
\hline
\end{tabular}

*Standard deviation $(\mathrm{n}=5)$ calculated in five replicates.

Table 5: Results of intra-assay and inter-assay

\begin{tabular}{lllll}
\hline $\begin{array}{l}\text { Conc. of escitalopram } \\
\text { (API) }(\boldsymbol{\mu g} / \mathbf{m l})\end{array}$ & \multicolumn{4}{l}{ Observed Conc. of escitalopram $(\boldsymbol{\mu g} / \mathbf{m l})$ by the proposed method } \\
\cline { 2 - 5 } & Intra-day assay & \% RSD & Inter-day assay \\
\cline { 2 - 5 } & Mean* $(\mathbf{n}=\mathbf{6})$ & 0.86 & 10.03 & \% $(\mathbf{n = 6})$ \\
\hline 10 & 10.01 & 0.30 & 30.03 & 0.87 \\
30 & 30.02 & 0.13 & 99.95 & 0.32 \\
100 & 99.97 & & 0.11 \\
\hline
\end{tabular}

*Mean $(\mathrm{n}=6)$

\section{Intra-assay and inter-assay}

The intra and inter-day variation of the method was carried out and the high values of mean assay and low values of standard deviation and $\%$ RSD $(\% \mathrm{RSD}<2 \%)$ within a day and day to day variations for escitalopram revealed that the proposed method is precise.

\section{Linearity and range}

Linearity indicates the ability of analytical procedures to produce results that are directly proportional to the concentration of analyte in the given sample.

\section{Preparation of stock solution (100 ppm)}

$25 \mathrm{mg}$ of escitalopram was dissolved in $25 \mathrm{ml}$ of the mobile phase, which gave a solution of the strength of $1000 \mathrm{ppm}$. $1 \mathrm{ml}$ of this solution was pipetted into a $10 \mathrm{ml}$ volumetric flask and the volume was made up to mark with diluents (mobile phase), which finally gave the stock solution of the strength of $100 \mathrm{ppm}$. The stock solution was degassed in an ultrasonic water bath for $5 \mathrm{~min}$ and filtered through a $0.45 \mu \mathrm{m}$ filter under vacuum filtration.

\section{Procedure}

Each level was injected into the chromatographic system and the peak area was measured. A graph of peak area versus concentration (on X-axis concentration and Y-axis peak area) was plotted and the correlation coefficient was calculated.

\section{Acceptance criteria}

Correlation coefficient should be not less than 0.999 .

\section{Calibration curve}

Linearity plot information

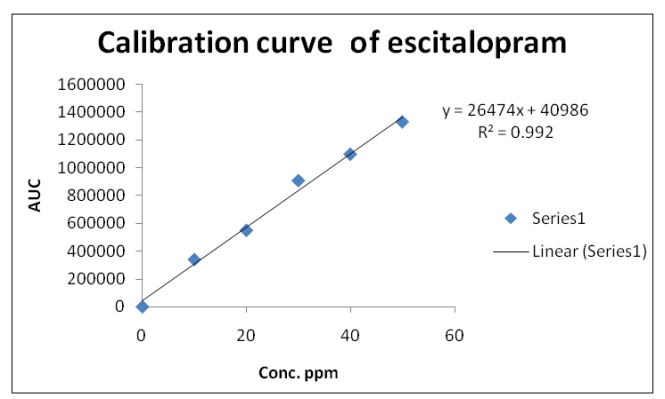

Fig. 4: Calibration curve of escitalopram (API)

The calibration curve showed good linearity in the range of $0-50$ $\mu \mathrm{g} / \mathrm{ml}$, for escitalopram (API) with a correlation coefficient $\left(\mathrm{r}^{2}\right)$ of 0.992 (fig. 4). A typical calibration curve has the regression equation of $y=26474 x+40986$ for escitalopram.

Table 6: Linearity results

\begin{tabular}{ll}
\hline Conc. & AUC (n=6) \\
\hline 0 & 0 \\
10 & 339085 \\
20 & 548749 \\
30 & 905740 \\
40 & 1095457 \\
50 & 1327962 \\
\hline
\end{tabular}

\section{Method robustness}

Influence of small changes in chromatographic conditions such as a change in flow rate $( \pm 0.1 \mathrm{ml} / \mathrm{min})$, temperature $\left( \pm 2{ }^{\circ} \mathrm{C}\right)$, the wavelength of detection $( \pm 2 \mathrm{~nm})$ and acetonitrile content in the mobile phase $( \pm 2 \%)$ studied to determine the robustness of the method are also in favour of (table $7, \% \mathrm{RSD}<2 \%$ ) the developed RPHPLC method for the analysis of escitalopram (API).

\section{LOD and LOQ}

The minimum concentration level at which the analyte can be reliably detected (LOD) and quantified (LOQ) were found to be 0.03 and $0.09 \mu \mathrm{g} / \mathrm{ml}$, respectively.

\section{Assay of escitalopram in dosage form}

Twenty tablets containing drug escitalopram having brand name Cipralex-10 mg were taken and the I. P. method was followed to determine the average weight. Above weighed tablets were finely powdered and triturated well. A quantity of powder equivalent to $100 \mathrm{mg}$ of drugs was transferred to $100 \mathrm{ml}$ volumetric flask, and 70 $\mathrm{ml}$ of diluents was added and the solution was sonicated for $15 \mathrm{~min}$, thereafter volume was made up to $100 \mathrm{ml}$ with the same solvent. Then $10 \mathrm{ml}$ of the above solution was diluted to $100 \mathrm{ml}$ with diluents. The solution was filtered through a membrane filter $(0.45$ $\mu \mathrm{m})$ and sonicated to degas. From this stock solution (1 ml) was transferred to five different $10 \mathrm{ml}$ volumetric flasks and volume were made up to $10 \mathrm{ml}$ with the same solvent system. The solution 
prepared was injected in five replicates into the HPLC system and the observations were recorded. A duplicate injection of the standard solution was also injected into the HPLC system and the peak areas were recorded. The data are shown in table 8 .

Table 7: Result of the method robustness test

\begin{tabular}{ll}
\hline Change in parameter & \% RSD \\
\hline Flow $(1.1 \mathrm{ml} / \mathrm{min})$ & 0.06 \\
Flow $(0.9 \mathrm{ml} / \mathrm{min})$ & 0.04 \\
Temperature $\left(27^{\circ} \mathrm{C}\right)$ & 0.08 \\
Temperature $\left(23^{\circ} \mathrm{C}\right)$ & 0.11 \\
Wavelength of detection $(213 \mathrm{~nm})$ & 0.03 \\
Wavelength of detection $(209 \mathrm{~nm})$ & 0.02 \\
\hline
\end{tabular}

$* \%$ RSD $<2 \%$

Table 8: Assay of escitalopram tablets

\begin{tabular}{llll}
\hline Brand name of the tablet & Labelled amount of drug (mg) & $\begin{array}{l}\text { Mean ( } \pm \text { SD) amount (mg) found } \\
\text { by the proposed method (n=6) }\end{array}$ & $\begin{array}{l}\text { Mean ( } \pm \text { SD) assay (n = 6) } \\
\text { Cipralex-10 mg }\end{array}$ \\
\hline
\end{tabular}

${ }^{*} \pm$ SD $(n=6)$ for the assay of tablets containing escitalopram was found to be $99.56 \%$.

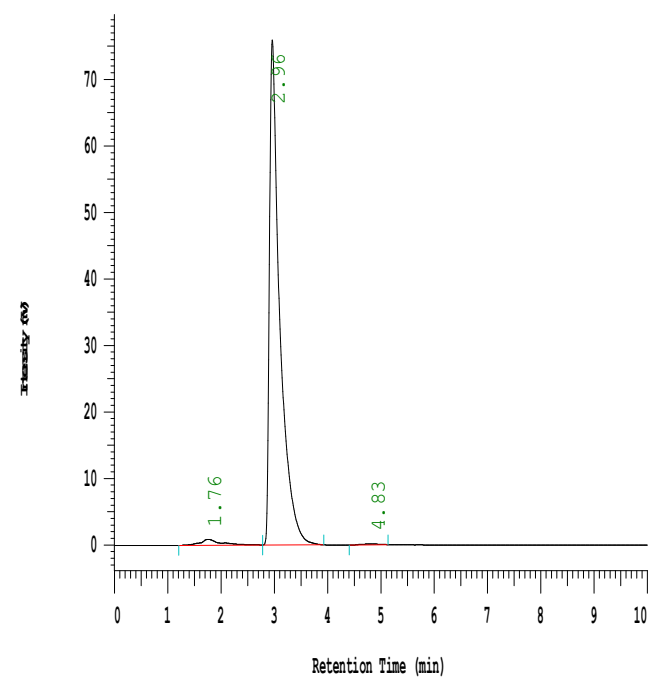

Fig. 5: Chromatogram showing peak of escitalopram in tablet formulation

\section{Dissolution profile}

Dissolution was done according to USP using the paddle dissolution apparatus. The dissolution test was performed in three different $\mathrm{pH}$ media of $1.2(0.1 \mathrm{~N} \mathrm{HCl}), 4.5$ and 6.8 phosphate buffer. The dissolution profiles were performed for the two prepared formulae to select the best

$\mathrm{f} 2=50 \log \{[1+(1 \backslash \mathrm{n}) \mathrm{Sn}(\mathrm{R}-\mathrm{T}) 2]-0.5 \times 100\} .(1)$

$\mathrm{f} 1=\{[\mathrm{Sn}|\mathrm{R}-\mathrm{T}|] /[\mathrm{Sn} \mathrm{R}]\} \times 100$. (2)

Table 9: Dissolution data of escitalopram

\begin{tabular}{ll}
\hline Time (min) & \% dissolved formula-1 \\
\hline 0 & $0 \pm .00$ \\
5 & $7 \pm 0.55$ \\
10 & $11.6 \pm 0.68$ \\
15 & $15.2 \pm 0.14$ \\
20 & $17.9 .7 \pm 0.36$ \\
25 & $19.8 \pm 0.27$ \\
30 & $20.8 \pm 0.61$ \\
35 & $21.9 \pm 0.62$ \\
40 & $22.7 \pm 0.49$ \\
45 & $23.4 \pm 0.50$ \\
\hline
\end{tabular}

$* \%$ dissolution studies done with $(\mathrm{n}=10)$ with respect to time in $\mathrm{min}$, the result shows a moderate dissolution $(23.4 \%)$ after $45 \mathrm{~min}$, but it reaches a plateau after approximately $25 \mathrm{~min}$. 


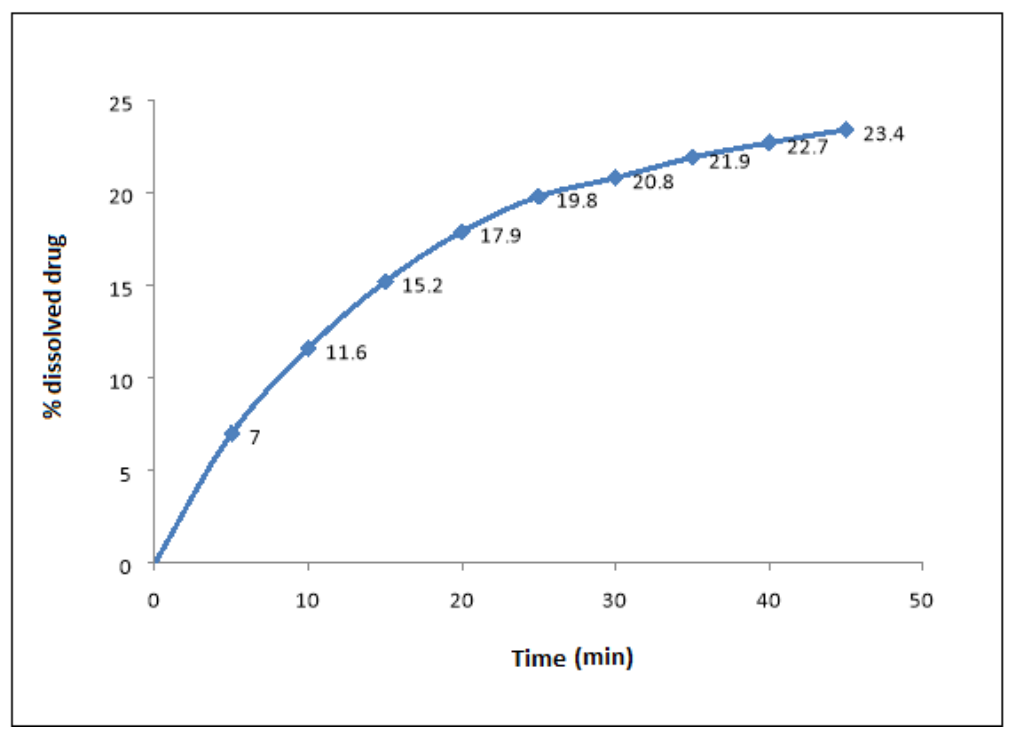

Fig. 6: Dissolution profile w. r. t. time

\section{DISCUSSION}

The various RP-HPLC methods have been studied for the analysis of escitalopram in bulk and various dosage forms [3-13]. However, the reported methods are less specific and also time-consuming. Therefore, we tried to develop a simple RP-HPLC method for the determination of escitalopram in bulk and its dosage form and also worked on the dissolution studies.

The sample preparation is a key step for accurate and reliable methods. The phosphate buffer is prepared by using potassium dihydrogen orthophosphate and the orthophosphoric acid is used to adjust the required $\mathrm{pH}$. We have taken almost five trials with different types of mobile phases and out of that we have selected the ACN: phosphate buffer $=60: 40(\mathrm{pH} 2.9)$ mobile phase, as it has given the good response as compare to the other methods, the indicative chromatogram is shown in the fig. 2 . The separation was carried out by $\mathrm{C}-18,150 \mathrm{~mm}$ column using mobile phase made up of phosphate buffer $(40 \%)$ and acetonitrile HPLC grade $(60 \%)$, the wavelength used is $211 \mathrm{~nm}$ with a flow rate of $1 \mathrm{ml} / \mathrm{min}$ and the injection volume $20 \mu$ l. The developed method was validated with different parameters such as linearity, precision, accuracy, robustness, the limit of detection (LOD), and limit of quantification (LOQ) according to ICH guidelines [15-17].

In the accuracy study, the SD found to be 0.171561, 0.045826, and 0.105987 the samples are analyzed in three replicates. The recovery study indicates that the average recovery is $99.36 \%$. The precision results also hold the passing criteria, and which is taken in five replicates \% RSD for the area of five standard injections results is not more than $2 \%$. The result of intra-assay and inter-assay shown in table no. 5 also confirms that the proposed method is precise. The linearity plot indicates good linearity in the concentration range of $0-50 \mu \mathrm{g} / \mathrm{ml}$ with a correlation coefficient (r2) of 0.992 . A typical calibration curve has the regression equation of $y=26474 x+40986$ is shown in fig. 4 .

The effect of small changes in chromatographic conditions such as the change in flow rate $( \pm 0.1 \mathrm{ml} / \mathrm{min})$, temperature $\left( \pm 2{ }^{\circ} \mathrm{C}\right)$, the wavelength of detection $( \pm 2 \mathrm{~nm})$ and acetonitrile content in the mobile phase $( \pm 2 \%)$ also studied to determine the robustness of the method, and are also in favour of developed method. The limit of detection (LOD) and limit of quantification (LOQ) were found to be 0.03 and $0.09 \mu \mathrm{g} / \mathrm{ml}$, respectively. As compared to the other developed methods the intra and inter-day assay was given a good result and it is found to be less than 2. The assay of tablets containing escitalopram was found to be $99.56 \%$. The fig. 5 shows the chromatogram of the tablet dosage form. The dissolution test was performed in three different $\mathrm{pH}$ media of $1.2(0.1 \mathrm{~N} \mathrm{HCl}), 4.5$ and
6.8 phosphate buffer respectively, and the study shows a moderate dissolution $(23.4 \%)$ after $45 \mathrm{~min}$, but it reaches a plateau after approximately $25 \mathrm{~min}$. Fig. 6 indicates the graphic representation of the dissolution study with respect to time (min).

\section{CONCLUSION}

The RP-HPLC method was developed for the analysis of escitalopram in standard and their pharmaceutical formulation and is found to be simple, rapid and economic with less run time. The method has been validated and it has been shown that it is reliable, linear, accurate and precise as well as robust with minor variations in chromatographic parameters. The in vitro dissolution results show a moderate dissolution $(23.4 \%$ ) after $45 \mathrm{~min}$, but it reaches a plateau after approximately $25 \mathrm{~min}$. Therefore, it will be applied for both routine analysis and quality control assay and it could be a very powerful tool to investigate the stability of escitalopram.

\section{ACKNOWLEDGEMENT}

First author thankful to Dr R. S Ghosh Dean, Dept. of Pharmacy, Carrier Point University, Kota, Rajasthan for continuous support during this research work.

\section{FUNDING}

Nil

\section{AUTHORS CONTRIBUTIONS}

All the authors have contributed equally to this study.

\section{CONFLICT OF INTERESTS}

Declared none

\section{REFERENCES}

1. Pastoor D, Gobburu J. Clinical pharmacology review of escitalopram for the treatment of depression. Expert Opin Drug Metab Toxicol 2014;10:121-8.

2. Sanchez C, Reines E, Montgomery S. A comparative review of escitalopram, paroxetine, and sertraline: are they all alike? Int Clin Psychopharmacol 2014;29:185-96.

3. Chusena N, Devala R, Pasupuleti U. Development and validation of an RP-HPLC method for the simultaneous determination of escitalopram oxalate and clonazepam in bulk and its pharmaceutical formulations. Int Curr Pharm J 2012;1:193-8.

4. Tapobana S, Dey S, Samal H, Bharat D, Mohanty D, Bhar K, et al. RP-HPLC method for the estimation of escitalopram in bulk and in dosage forms. Int J Chem Res 2011;2:11-5. 
5. Subash P, Anbazhagan S, Rishop R, Valarmathy S, Winkumar G, Suriya R, et al., RP-HPLC method development and validation for the determination of escitalopram oxalate and clonazepam in tablet dosage form. Int J Res Pharm Pharm Sci 2018;3:35-44.

6. Kakde R, Satone D, Gadapayale K, Kakde M. Stability-indicating RP-HPLC method for the simultaneous determination of escitalopram oxalate and clonazepam. J Chromatogr Sci 2013;51:490-5.

7. Nekkala K, Shanmukha J, Ramachandran D, Ramanaiah G, Srinivas G. Method development and validation of stability indicating RP-HPLC method for simultaneous estimation of escitalopram oxalate and etizolam in bulk and its pharmaceutical formulations. Int J Bioassays 2014;3:3456-63.

8. Bindusar K. Method development and validation of stability indicating RP-HPLC method for simultaneous estimation of escitalopram oxalate and clonazepam in bulk and its pharmaceutical formulations. J Drug Delivery Ther 2019;9:265-74

9. Mondal P, Santhosh B, Satla S, Raparla R. A new validated simultaneous RP-HPLC method for estimation of escitalopram oxalate and etizolam in bulk and table dosage form. Der Pharm Chem 2013;5:26-32.

10. Damor S, Patel D. Stability-indicating chromatographic method development and validation for the simultaneous estimation of escitalopram oxalate and flupentixol in its pharmaceutical dosage form by HPLC. World J Pharm Res 2017;6:549-66.

11. Krishna V, Gouthami B, Meyyanathan S, Gowramma B, Elango $\mathrm{K}$, Suresh $\mathrm{B}$, et al., In vitro in vivo pharmacokinetic interaction study of escitalopram oxalate when co-administered with caffeine/caffeinated beverages. Open Conference Proceedings 2013;4:66-71.

12. Bhimanadhuni C, Garikapati D, Usha P. Development and validation of an RP-HPLC method for the simultaneous determination of escitalopram oxalate and clonazepam in bulk and its pharmaceutical formulations. Int Curr Pharmaceutical J 2012;5:193-8.

13. Kalia B, Baghel U. Method development and validation of stability indicating RP-HPLC method for simultaneous estimation of escitalopram oxalate and clonazepam in bulk and its pharmaceutical formulations. J Drug Delivery Ther 2019;15:265-74.

14. Mahadik M, Dhaneshwar S, Kulkarni M. Application of stabilityindicating HPTLC method for the quantitative determination of escitalopram oxalate in pharmaceutical dosage form. Eurasian J Anal Chem 2007;2:101-17.

15. ICH, Q2A validation of analytical procedure: international methodology conference on harmonization, Geneva; 1994.

16. ICH, Q2B Validation of analytical procedure: international methodology conference on harmonization, Geneva; 1996.

17. ICH Guidance on Analytical Method Validation. In: Proceedings of the International Convention on Quality for the Pharmaceutical Industry, Toronto, Canada; 2002.

18. Patel S, Maheshwari D. Development and validation of UV spectrometric and HPLC method for estimation of escitalopram oxalate and flupentixol dihydrochloride in combined dosage form. Asian J Pharm Technol Innovation 2016;4:59-70. 